\title{
Distribution of Biomphalaria Snails in Associated Vegetations and Schistosome Infection Prevalence Along the Shores of Lake Victoria in Mbita, Kenya: A Cross-Sectional Study
}

\author{
Sabiano O Odero, ${ }^{a}$ Lilian Ogonda, ${ }^{a}$ David Sang, ${ }^{a}$ Elly O Munde, ${ }^{a, b}$ Clement Shiluli, ${ }^{a}$ Patrick Chweya ${ }^{a}$ \\ aDepartment of Biomedical Sciences and Technology, School of Public Health and Community Development, Maseno University, Maseno, Kenya; bSchool of Health \\ Sciences, Kirinyaga University, Kerugoya, Kenya \\ Correspondence to Lilian Ogonda (lilianogonda@gmail.com)
}

\begin{abstract}
Background: Schistosomiasis due to Schistosoma mansoni remains a major public health problem and cause of morbidity and mortality in sub-Saharan Africa despite the implementation of control programmes. More than 6 million Kenyans are at risk of infection. Regarding control measures, Biomphalaria snail species, which are the obligatory intermediate hosts for transmission of S. mansoni, have been neglected. Mbita subcounty in Homa Bay County, western Kenya, along Lake Victoria basin, has a high prevalence of $S$. mansoni infection despite mass drug administration. This study aimed to determine the abundance of Biomphalaria, with their associated vegetation and schistosome infection rates, along Mbita shoreline.

Methods: Sixteen purposively selected sites along the Mbita shoreline were sampled for Biomphalaria snails using a 30-minute scooping technique. Global positioning system technology was used to map selected sites. The associated vegetation at sampling sites were collected and identified. Schistosome infection status among the snails was determined via the detection of cercaria shedding.

Results: A total of 3,135 Biomphalaria sudanica snails were collected. The number of snails collected differed significantly between the 16 sites $(F=11.735$; degrees of freedom $[\mathrm{df}]=15.836 ; P<.001)$. Significant mean differences $(M D)$ were also observed in terms of the number of snails collected per vegetation type $(F=7.899 ; d f=5.846 ; P<.001)$. The mean number of snails collected from Cyprus gracilis was significantly higher than that from Enydra fluactuants $(M D=2.03 ; P<.001)$, Eichhornia crassipes $(M D=4.15 ; P<.010)$, and $E$. fluactuants mixed with $E$. crassipes $(M D=2.516 ; P<.010)$. A total of $21(0.67 \%)$ snails shed human cercariae, while $27(0.86 \%)$ snails shed nonhuman cercariae, despite 14 sites having human faeces contamination.

Conclusion: Although the schistosome infection prevalence among the snails was low, these sites may still be important exposure sites. C. gracilis is the main vegetation type associated with a high abundance of Biomphalaria snails. Molecular techniques are necessary for verification of schistosome positivity among the snails.
\end{abstract}

\section{INTRODUCTION}

Chistosomiasis is a parasitic disease infecting 243 $\checkmark$ million people worldwide and is endemic in 78 countries with over $85 \%$ of cases occurring in sub-Saharan Africa. ${ }^{1}$ About 779 million people - more than $10 \%$ of the world's population are at risk of being infected with schistosomiasis. ${ }^{2}$ In Africa schistosomiasis is predominantly due to Schistosoma mansoni and Schistosoma haematobium which causes intestinal and urinary schistosomiasis respectively. ${ }^{3}$ Schistosomiasis caused by $S$. mansoni and S. haematobium are the 2 species found along the Kenyan lake Victoria region, ${ }^{4}$ with the intermediate host being snails of the genus Biomphalaria and Bulinus and respectively. ${ }^{5}$ S. mansoni infection continues to be among the most important and widespread of the neglected tropical diseases in Kenya, especially among communities living around the shores of Lake Victoria in western Kenya. ${ }^{4}$ More than 6 million people in Kenya are infected with the disease. ${ }^{6}$ Previous studies among school children in Mbita and its adjacent islands of Lake Victoria have shown the prevalence to be $63.3 \%$ and $60.5 \%$, respectively. ${ }^{7,8}$ Schistosomiasis has a great impact on the quality of life of individuals with important implication on the economy. ${ }^{9} S$. mansoni infection is known to lower cognitive development in children thereby lowering their academic performance in school and reduce work force in adults. ${ }^{6}$ In addition, $S$ mansoni infection can lead to hepatic periportal fibrosis in some patients which is a life-threatening complication. ${ }^{6}$ 
Mbita subcounty is an area on the shores of Lake Victoria whose waters are reported to be infested with intermediate snail hosts that transmit schistosomes. Most residents who live around the Lake Victoria shoreline of Mbita subcounty come into regular contact with the Lake water for their recreational activities, domestic use and are likely to be exposed to infection. Documented prevalence of $S$. mansoni remains high at approximately $60 \%,{ }^{10}$ despite the existence of control programs against schistosomiasis including mass drug administration (MDA), education, water and sanitation programs in Mbita. Studies on schistosome infection prevalence of Biomphalaria snails along Lake Victoria shoreline of Mbita is necessary for identification of exposure sites in order to direct intervention to the areas.

Several species of snails of the genus Biomphalaria are obligatory intermediate host for the transmission of S. mansoni. Biomphalaria sudanica is the species which is commonly found along the shores of Lake Victoria while Biompharia chaonomphala is found in the lake bed. ${ }^{9}$ The natural habitat of Biomphalaria species except Biomphalaria chaonomphala are shallow stagnated water with little current near the shores of the Lakes, ponds, marshes, streams and irrigation channels. ${ }^{11}$ They live on water plants and mud and are most common in waters where plants are abundant and moderately polluted by organic matter such as urine and feces as is often near human habitation. ${ }^{9}$ Within each habitat their local distribution is usually patchy, and requires examination of different sites. ${ }^{10}$ Studies have shown that microhabitat factors such as protection from water flow, wave action, availability of food, presence of vegetation and stable surface for attachment influence the presence and abundance of intermediate host snails. ${ }^{12}$ Different species of aquatic vegetation such as water hyacinth (Eichhornia crassipes), water lily (Nyamphea spp.), hippo grass and short grasses have been associated with the presence of the intermediate snail hosts in other areas. ${ }^{13}$ The detection of Biomphalaria snails infected with schistosomes is usually performed by cercarial shedding and eventual examining of the shed cercariae under a dissecting microscope for species identification. ${ }^{9}$ Since Biomphalaria snail species act as intermediate host, knowledge on their abundance is an essential prerequisite towards the understanding S. mansoni disease transmission and control. However no study has been done to determine the abundance of Biomphalaria host snails along the Lake Victoria shoreline of Mbita, Homa Bay County. Moreover, no vegetation type has been linked with high snail abundance in this region. The purpose of the study was to determine the abundance of Biomphalaria with their associated vegetation and to determine schistosome infection of the snails along Mbita shoreline.

\section{METHODS}

\section{Study Area}

The study was conducted in Health Demographic Surveillance System (HDSS) Mbita, located in Mbita subcounty, which is 1 of the 5 subcounties of Homa Bay County in western Kenya. The area is located on the shores of Lake Victoria. The HDSS Mbita covers an area of $163.28 \mathrm{~km}^{2}$ and is between latitudes $0^{\circ} 21^{\prime}$ and $0^{\circ} 32^{\prime}$ South, and longitudes $34^{\circ} 04^{\prime}$ and $34^{\circ} 24^{\prime}$ East. This HDSS area comprises: Gembe East, Gembe West, Rusinga East and Rusinga West locations which are part of the 5 locations in Mbita subcounty. The HDSS in Mbita follows 11,182 households with a population of 55,929 individual. ${ }^{7}$ The ethnic group in this area is predominantly Luo (98\%). There are 30 health facilities within the study area. The main economic activities in the area are fishing and subsistence farming. The annual rainfall in Mbita district is between 800-1900 $\mathrm{mm}$. However, the rains are slightly lower in Rusinga Island with an annual range of 800 to 1,200 $\mathrm{mm}$. The long rains start from March to May while the onset of short rains is from September to December. The temperatures in this region ranges from $15^{\circ} \mathrm{C}$ to $30^{\circ} \mathrm{C}$ (Mbita Strategic plan 2008-2012).

\section{Study Design}

This was a cross sectional study that aimed at determining the abundance of Biomphalaria snails in 16 purposively selected study sites; assess vegetation types associated with abundance of vector snail and schistosome infection prevalence of Biomphalaria snails from each of the sites. Selected sites were mapped using hand held differential geographical global positioning system (GPS).

The 16 sites were purposively selected based on the following: where people had direct water contact due to their routine activities such as swimming, collecting water for domestic use, bathing, washing and occupational work like fishing or farming. The surrounding of the selected sites was assessed for the presence of human faeces.

\section{Collection of Biomphalaria Snails}

Only Biomphalaria host snails were collected using hand held standard flat wire mesh scoop (2 mm mesh size), according to previously described method.5,10,13 The sampling site was measured $20 \mathrm{~m}$ long, along the lake shore and $2 \mathrm{~m}$ long into the main water body. The total area of the site scooped was $40 \mathrm{~m}^{2}$ and scooping was performed in each and every site between 7:00 am and 9:30 am. The scoop was pushed under the vegetation once, lifted up when still under the vegetation and then shaken 3 times so that the snails were dislodged from the vegetation roots onto the scoop and then the scoop was withdrawn outside. With the help of a forceps, the vector snails were picked 1-by-1 as they were counted and recorded per scoop and then put in a perforated plastic container for transportation to the laboratory. The vegetation from which each scoop was pushed under during sampling was also recorded. The total number of snails collected per site was reported in meters square $\left(\mathrm{m}^{2}\right)$. Time of starting and ending collection per every site were noted down. 


\section{Biomphalaria Species Identification}

Biomphalaria intermediate host snails collected from the selected sites were taken to Nagasaki University Laboratory at Mbita for identification according to WHO snail identification guide. ${ }^{14}$

\section{Screening of Snails for Schistosome Infection}

To determine whether the host snails were positive for schistosome cercariae, Biomphalaria snails were singly put in a 24 well culture plates containing $2 \mathrm{ml}$ of clean and clear water and then exposed to bright artificial light for 3 hours. After the shedding period was over, the wells containing snails were put under Olympus dissecting microscope and each well with snail inside was checked for shed cercariae which had the tendency of up and down movement using forked coiled tail. ${ }^{15}$ Human and animal cercariae were identified based on their distinct morphological features. Nonshedding snails were returned to the aquaria until the following day when they were again exposed to bright artificial light for 3 hours and were then re-examined under the dissecting microscope before declaring them negative.

\section{Vegetation Associated With Distribution of Biomphalaria Snails}

A sample of vegetation types at each sampling site was collected and taken to Kenya Marine and Fisheries Research Institute (KEMFRI), Kisumu, for identification. The vegetation types from which the snails were scooped were: Buffalo spinach (Enydra fluactuants), water hyacinth (E. crassipes) and Sedge (C. gracilis).

\section{Statistical Analysis}

All statistical analyses were performed using SPSS Statistics version 23.0 (IBM Corp., Armonk, NY, USA). Analysis of variance (ANOVA) was used to compare mean differences (MDs) in snail abundance between different sites and associated vegetation type. Significant differences in mean number of snails collected per site and associated vegetation type was determined using Tukey's post hoc test.

\section{Ethical Considerations}

The study was approved by the Maseno University Ethics review Committee (MUREC). Ethical approval reference number MSU/DRPI/MUERC/00256/15.

\section{RESULTS}

\section{Abundance of $B$. sudanica Snails Per Site}

Table 1 summarises the results on the numbers of snails infected with human and nonhuman cercariae as determined per site. A total of 3,135 B. sudanica snails were collected from the 16 different sampling sites. The number of snails collected differed significantly between the 16 sites $(\mathrm{F}=11.735$; degrees of freedom $[\mathrm{df}]=15.836 ; P<.001)$. The lowest snail collection was realised at Bau $(\mathrm{n}=59 ; \mathrm{M}=0.73)$ and the most at Orundu $(\mathrm{n}=356 ; \mathrm{M}=11.87)$, with Tukey's post hoc test indicating that the mean number of snails collected at Orundu differed significantly from all other sites $(P<.001)$.

\section{Schistosome Infection Prevalence of B. sudanica Snails Per Site}

Out of the 3,135 B. sudanica snails that were collected, only 21 $(0.67 \%)$ shed human cercariae, and $27(0.86 \%)$ shed nonhuman cercariae. However, no significant difference was found in the proportion of snails positive for cercariae between the sites $(P=.338)$. Moreover, human faeces were detected in all the sites except Bau and Kosata. The results are summarised in Table 1.

\section{Distribution of B. sudanica Snails Per Pure and Mixed Vegetation}

Table 2 shows the distribution of B. sudanica in pure and mixed vegetation types. There were significant differences in abundance of $B$. sudanica snails based on different vegetation types. Based on pure vegetation, the mean number of $B$. sudanica snails collected from C. gracilis was significantly higher than those from E. crassipes ( $\mathrm{MD}=4.15 ; 95 \% \mathrm{CI}, 0.65$ to $7.65 ; P=.01$ ), and E. fluactuants ( $\mathrm{MD}=2.03 ; 95 \% \mathrm{CI}, 0.69$ to $3.37 ; P<.001)$. There were also significant differences in the number of snails between $C$. gracilis combination with E. fluactuants versus E. fluactuants combination with E. crassipes ( $\mathrm{MD}=4.71 ; 95 \% \mathrm{CI}, 1.14$ to $8.27 ; P=.002)$. These findings suggest that $C$.gracilis is the main vegetation type associated with highest number of Biomphalaria snails in the 16 sites studied.

\section{DISCUSSION}

Our investigation on the vegetation types and schistosome infection of B. sudanica have indicated varied observations in 16 sites, in shores along Lake Victoria shores of Mbita, Kenya. The results of the current study demonstrated high abundance of B. sudanica host snail vectors of $S$. mansoni from the selected sites. Orundu and Bau sites had the highest and lowest snail collection respectively. Examination of distribution of snails based on vegetation type revealed that there were more snails in the C. gracilis relative to E. crassipes and E. fluactuant while mixed vegetation showed that E. crassipes together with $C$. gracilis relative to E. fluactuants combination with E. crassipes had higher number of snails. 
TABLE 1. Number of Biomphalaria Snails and Their Schistosome Infection Prevalence

\begin{tabular}{ccccc}
\hline Site & Snail Count & $\begin{array}{c}\text { Human Schistosomes } \\
\mathbf{n}(\%)\end{array}$ & $\begin{array}{c}\text { Nonhuman } \\
\text { Schistosomes } \\
\mathbf{n}(\%)\end{array}$ & $\begin{array}{c}\text { Presence of Human } \\
\text { Faeces } \\
\text { (Positive/Negative) }\end{array}$ \\
\hline Koguna & 328 & 0 & $5(1.52)$ & positive \\
W. Bur-B & 238 & 0 & $4(1.66)$ & positive \\
Orundu & 356 & $2(0.56)$ & 0 & positive \\
Kochola & 177 & 0 & $3(1.70)$ & positive \\
Ngou & 187 & 0 & $2(1.15)$ & positive \\
Wakondo & 151 & $3(1.50)$ & 0 & positive \\
Uyoga & 118 & $4(3.34)$ & $2(1.68)$ & positive \\
Kosata & 174 & 0 & $3(1.69)$ & negative \\
Kobara & 139 & 0 & 0 & positive \\
Kombe-B & 339 & 0 & 0 & positive \\
Kalea & 171 & 0 & 0 & positive \\
Nyagina & 175 & $4(2.30)$ & $2(1.15)$ & positive \\
Kombe-A & 116 & $5(4.67)$ & 0 & positive \\
Kigoda & 121 & 0 & 0 & positive \\
Bau & 59 & $3(2.12)$ & 0 & negative \\
W. Bur-A & 286 & $\mathbf{2 1}(0.67)$ & $\mathbf{2 7}$ & positive \\
Total & 3,135 & $27.12)$ &
\end{tabular}

Twenty-one (0.67\%) of the B. sudanica snails shed human cercariae, and $27(0.86 \%)$ shed nonhuman cercariae, but no significance difference was found in the proportion of snails positive for cercariae between the sites $(P=.338)$.

TABLE 2. Biomphalaria sudanica Abundance According to Vegetation Type

\begin{tabular}{lccc}
\hline \multicolumn{1}{c}{ Vegetation Type } & Mean Difference & 95\% Confidence Interval & P Value \\
\hline Pure vegetation & & & .010 \\
CG Vs EC & 4.15 & $0.65-7.65$ & $<.001$ \\
CG vs EF & 2.03 & $0.69-3.37$ & .474 \\
EC vs EF & -2.17 & $-5.50-1.27$ & \\
Mixed vegetation & & & .722 \\
ECCG vs EFCG & -1.91 & $-5.70-1.96$ & .464 \\
ECCG vs EFEC & 2.80 & $-1.63-7.23$ & .002 \\
EFCG vs EFEC & 4.71 & $1.14-8.27$ & \\
\hline
\end{tabular}

Mean differences in the distributions of Biomphalaria snails according to pure vegetation and mixed vegetation were determined using Tukey's post hoc test. Abbreviations: CG, Cyprus gracilis; EC, Eichhornia crassipes; EF, Enydra fluactuants; ECCG, Eichhornia crassipes/Cyprus gracilis; EFCG, Enydra fluactuants/

Cyprus gracilis; EFEC, Enydra fluactuants/Eichhornia crassipes 
This study results concur with that of Standley and coworkers ${ }^{16}$ on the distribution of Biomphalaria (Gastropoda: Planorbidae) along the shoreline of Lake Victoria of Kenya, Uganda and Tanzania that showed not only are B. sudanica snails widely found around the shoreline of Lake Victoria, but also their distribution is heterogeneous on a local scale. This however contradicts a previous study,,$^{10}$ which concluded that there could be only about 10-15 snails per site sampled. Furthermore, this study showed that the number of snails collected after 30 minutes of scooping in an area of $40 \mathrm{~m}^{2}$ from the selected sites was more compared to other studies. The lower numbers could be due to improper snail sampling techniques which is not standardised, lack of proper identification of vegetation preferred by snails or the area of the site covered. It has earlier on been demonstrated that snails have preference to vegetation from where they get shelter, protection from the waves and also egg laying. ${ }^{16}$ From this study, it is scientifically plausible that since $B$. sudanica vector snails are found in the vegetation along the shoreline next to the open beaches where people frequent for fishing, water harvesting and swimming, such places may be important transmission points taking into account that human faeces were also found around the selected sites.

In the current study, we further demonstrated that of the 3,135 snails collected only $0.67 \%$ shed human cercariae while $0.86 \%$ shed nonhuman cercariae. The result shows that there was very low percentage of $B$. sudanica host snails shedding human cercariae even though all the sites except 2 had human faeces around them. It would be important that future study includes collection and $S$. mansoni eggs examination of faeces from site residents to help confirm possibility of $S$. mansoni foci of transmission. Taking into account that our current study area has high schistosomiasis transmission, ${ }^{8}$ it was rather surprising to find that very few vector snails shed human cercariae. It is important to appreciate that presence of the snail does not necessarily mean that they are also infected. However, the findings of this study is consistent with other previous study results from endemic areas with high transmissions where snail vector infection with cercariae were low and even some places had no single snail shedding cercariae ${ }^{17}$ on host snail vectors of $S$. mansoni. This study further concurs with earlier study findings ${ }^{18}$ which revealed that in the Lake Victoria basin Western Kenya, only $1.04 \%$ of the total collected vector snails from different sites shed cercariae. Furthermore, an additional epidemiological study in Uganda Sesse island, did not find any Biomphalaria snails shedding schistosome cercariae. ${ }^{19}$ Studies continue to come up with explanation concerning these findings: First, the development of parasite inside the vector snails has stages. ${ }^{20}$ After penetration of the miracidium into the host snail, it develops into primary and secondary sporocysts that hence liberate mature cercariae and this takes approximately 4 weeks, ${ }^{15}$ so it depends at what stage the vector snail was collected. Secondly, in the prepatent period very few snails will shed cercariae, ${ }^{21}$ therefore identification of vector infection cannot be performed by classical detection (shedding). ${ }^{9}$ Although classical detection is routinely used in the laboratories for identification of human schistosome-infected vector snails, few snails are always found shedding human cercariae and it is worth noting that molecular techniques could be the most accurate method in determining positive Biomphalaria host snails both in their prepatent and patent stages of infection..$^{22-24}$

In determining the abundance of snails based on the vegetation types, the results revealed that there were higher number of snails in the C. gracilis relative to E. crassipes and E.fluactuants. This finding implies snails' preference to $C$. gracilis. When mixed vegetation was compared, E. crassipes together with C. gracilis relative to E. fluactuants combination with E. crassipes had higher number of snails. In addition, a study by Angelo and colleagues ${ }^{25}$ showed that the abundance and disease transmission potential of snail intermediate host of human schistosomiasis in fishing community of Mwanza were common in E. crassipes. On the contrary, more snails have been shown to be found in Echinochloa stagnina mixed with E. crassipes along the shoreline of Lake Victoria. ${ }^{5}$ Rather than feeding directly on higher plants, snails are known to feed by grinding the decaying plants matter, microflora, algae and bacteria that covers the vegetation. ${ }^{26}$ Therefore C. gracilis being soft grass, the rate of drying and decaying is high and the growth of algae and other microflora on the decaying materials will be on the increase. Due to the availability of food -especially algae, the population of vector snails is most likely to rise. We therefore, from our current study demonstrate that the $C$. gracilis is the vegetation of choice for the vector snails. Moreover, its combination with E. fluactuants could be more favourable for snails. Further studies should consider vegetation as important determinants snail distribution.

\section{CONCLUSION}

The study revealed that $C$. gracilis is the main vegetation type associated with a high abundance of Biomphalaria snails. Although schistosome infection prevalence among the snails was low, these sites may still be important exposure sites. Molecular techniques are necessary for the verification of schistosome positivity among snails.

Acknowledgements: All the authors thank the local community for cooperation during sample collection. We are indebted to all Maseno University Biomedical Sciences laboratory staff for support in performances of various laboratory experiments.

\section{REFERENCES}

1. World Health Organization (WHO). Schistosomiasis. WHO Website. https:// www.who.int/en/news-room/fact-sheets/detail/schistosomiasis.

2. Bruun B, Aagaard-Hansen J, Watts S. The Social Context of Schistosomiasis and its Control: An Introduction and Annotated Bibliography. Geneva: WHO; 2008.

3. Brooker S, Kabatereine NB, Smith JL, et al. An updated atlas of human helminth infections: the example of East Africa. Int J Health Geogr. 2009;8:42. CrossRef. Medline 
4. Handzel T, Karanja DM, Addiss DG, et al. Geographic distribution of schistosomiasis and soil-transmitted helminths in Western Kenya: implications for anthelminthic mass treatment. Am J Trop Med Hyg. 2003;69(3):318-323. Medline

5. Ofulla AV, Adoka SO, Anyona DN, et al: Spatial distribution and habitat characterization of schistosomiasis host snails in lake and land habitats of western Kenya. Lakes Reservoirs Res Manag. 2013;18(2):197-215. CrossRef

6. Mutahi WT, Thiong'o FW. Prevalence and intensity of Schistosomiasis mansoni in irrigation and non-irrigation areas of central Kenya. East Afr Med J. 2005;82(1 1):586-591. CrossRef. Medline

7. Nagi S, Chadeka EA, Sunahara T, et al. Risk factors and spatial distribution of Schistosoma mansoni infection among primary school children in Mbita District, Western Kenya. PLoS Negl Trop Dis. 2014;8(7):e2991. CrossRef. Medline

8. Odiere MR, Rawago FO, Ombok M, et al. High prevalence of schistosomiasis in Mbita and its adjacent islands of Lake Victoria, western Kenya. Parasit Vectors. 2012;5:278. CrossRef. Medline

9. Kariuki HC, Clennon JA, Brady MS, et al. Distribution patterns and cercarial shedding of Bulinus nasutus and other snails in the Msambweni area, Coast Province, Kenya. Am J Trop Med Hyg. 2004;70(4):449-456. Medline

10. Opisa S, Odiere MR, Jura WG, Karanja DM, Mwinzi PN. Malacological survey and geographical distribution of vector snails for schistosomiasis within informal settlements of Kisumu City, western Kenya. Parasit Vectors. 2011;4:226. CrossRef. Medline

11. Kazibwe F, Makanga B, Rubaire-Akiiki C, et al. Ecology of Biomphalaria (Gastropoda:Planorbidae) in Lake Albert, western Uganda: snail distributions, infection with schistosomes and temporal associations with environmental dynamics. Hydrobiologia. 2006;568:433-444. CrossRef

12. Monde C, Syampungani S, van den Brink PJ. Natural and human induced factors influencing the abundance of schistosoma host snails in Zambia. Environ Monit Assess. 2016;188(6):370. CrossRef. Medline

13. Ofulla $A V O$, Karanja $D$, Omondi $R$, et al. Relative abundance of mosquitoes and snails associated with water hyacinth and hippo grass in the Nyanza gulf of Lake Victoria. Lakes Reservoirs Res Manag. 2010;15(3):255-227. CrossRef

14. Barbosa FS, Berry EG, Harry HW, et al. A Guide for the Identification of the Snail Intermediate Hosts of Schistosomiasis in the Americas. Scientific Publication No. 168. Washington, DC: Pan American Health Organization;1968.

15. Sturrock RF, Diaw OT, Talla I, Niang M, Piau JP, Capron A. Seasonality in the transmission of schistosomiasis and in populations of its snail intermediate hosts in and around a sugar irrigation scheme at Richard Toll, Senegal. Parasitology. 2001;123 suppl:S77-S89. CrossRef. Medline

16. Standley CJ, Vounatsou P, Gosoniu L, et al. The distribution of Biomphalaria (Gastropoda: Planorbidae) in Lake Victoria with ecological and spatial predictions using Bayesian modelling. Hydrobiologia. 2012;683(1):249-264. CrossRef

17. Standley CJ, Goodacre SL, Wade CM, Stothard JR. The population genetic structure of Biomphalaria choanomphala in Lake Victoria, East Africa: implications for schistosomiasis transmission. Parasit Vectors. 2014;7:524. CrossRef. Medline
18. Steinauer ML, Mwangi IN, Maina GM, et al. Interactions between natural populations of human and rodent schistosomes in the Lake Victoria region of Kenya: a molecular epidemiological approach. PLoS Negl Trop Dis. 2008;2(4):e222. CrossRef. Medline

19. Standley CJ, Adriko M, Arinaitwe M, et al. Epidemiology and control of intestinal schistosomiasis on the Sesse Islands, Uganda: integrating malacology and parasitology to tailor local treatment recommendations. Parasit Vectors. 2010;3(1):64. https://doi.org/10.1186/1756-3305-3-64. https://www.ncbi. nlm.nih.gov/pubmed/20663223

20. O'keeffe JH. Population biology of the freshwater snail Bulinus globosus on the Kenya Coast. I. population fluctuations in relation to climate. J Appl Ecol. 1985;22(1):73-84. CrossRef

21. Sow S, de Vlas SJ, Stelma F, Vereecken K, Gryseels B, Polman K. The contribution of water contact behavior to the high Schistosoma mansoni Infection rates observed in the Senegal River Basin. BMC Infect Dis. 2011;11:198. CrossRef. Medline

22. Hamburger J, Weil M, Ouma JH, Koech D, Sturrock RF. Identification of schistosome-infected snails by detecting schistosomal antigens and DNA sequences. Mem Inst Oswaldo Cruz. 1992;87 suppl 4:243-247. CrossRef. Medline

23. Pontes LA, Dias-Neto E, Rabello A. Detection by polymerase chain reaction of Schistosoma mansoni DNA in human serum and feces. Am J Trop Med Hyg. 2002;66(2):157-162. CrossRef. Medline

24. Xu J, Rong R, Zhang $H Q$, Shi $C J$, Zhu $X Q$, Xia $C M$. Sensitive and rapid detection of Schistosoma japonicum DNA by loop-mediated isothermal amplification (LAMP). Int J Parasitol. 2010;40(3):327-331. CrossRef. Medline

25. Angelo T, Shahada F, Kassuku A, et al. Population abundance and disease transmission potential of snail intermediate hosts of human schistosomiasis in fishing communities of Mwanza Region, North-western, Tanzania. Int J Sci Res. 2014;3(8):1230-1236.

26. Klumpp RK, Chu KY. Importance of the aquatic weed Ceratophyllum to transmission of Schistosoma haematobium in the Volta Lake, Ghana. Bull World Health Organ. 1980;58(5):791-798. Medline

\section{Peer Reviewed}

Competing Interests: None declared.

Received: 11 Jan 2019; Accepted: 11 Sep 2019

Cite this article as: Odero SO, Ogonda L, Sang D, Munde EO, Shiluli C, Chweya P. Distribution of Biomphalaria Snails in Associated Vegetations and Schistosome Infection Prevalence Along the Shores of Lake Victoria in Mbita, Kenya: A Cross-Sectional Study. East Afr Health Res J. 2019;3(2):172-177. http://doi.org/10.24248/ EAHRJ-D-19-00013.

(C) Odero et al. This is an open-access article distributed under the terms of the Creative Commons Attribution License, which permits unrestricted use, distribution, and reproduction in any medium, provided the original author and source are properly cited. To view a copy of the license, visit http://creativecommons.org/licenses/ by/4.0/. When linking to this article, please use the following permanent link: http:// doi.org/10.24248/EAHRJ-D-19-00013. 